\title{
HPLC DETERMINATION OF EZETIMIBE AND SIMVASTATIN IN PHARMACEUTICAL FORMULATIONS
}

\author{
MUHAMMAD ASHFAQ ${ }^{* A}$, ISLAM ULLAH KHAN ${ }^{A}$, SYED SHANAZ QUTAB ${ }^{B}$, SYED NAEEM RAZZAQ ${ }^{B}$,
}

\author{
${ }^{a}$ Department of Chemistry, Government College University, Lahore-54000, Pakistan.

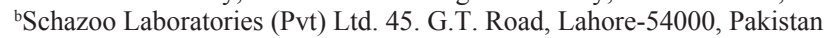

(Received $28^{\text {th }}$ February 2007 - Accepted $2^{\text {nd }}$ May 2007)

\begin{abstract}
A simple, precise and sensitive reverse-phase high performance liquid chromatographic method was developed and validated for the simultaneous determination of ezetimibe and simvastatin in pharmaceutical formulations. Chromatographic separation was performed on a Merck C18 column at a wavelength of $240 \mathrm{~nm}$ using a mixture of $0.1 \mathrm{M}$ ammonium acetate buffer $\mathrm{pH} 5.0$ and acetonitrile in the ratio of $(30: 70, \mathrm{v} / \mathrm{v})$. The method results in excellent separation with good resolution between the two analytes. The within day variation was between 0.28 and $1.10 \%$ and between day variation was between 0.56 and $1.32 \%$. The recovery was greater than $99.12 \%$ with RSD less than $1.38 \%$. The method was validated according to ICH guidelines by performing linearity, accuracy, precision, limits of quantitation and selectivity. The results show that the method is suitable for its intended use.
\end{abstract}

Key words: HPLC, acetonitrile, isocratic, ezetimibe, simvastatin.

\section{INTRODUCTION}

Simvastatin (Fig. 1), a hypolipidemic drug belonging to the class of pharmaceuticals called statins is chemically designated as $[(1 \mathrm{~S}, 3 \mathrm{R}, 7 \mathrm{R}, 8 \mathrm{~S}, 8 \mathrm{aR})-$ 8-[2-[(2R,4R)-4-hydroxy-6-oxo-oxan-2-yl]ethyl]-3,7-dimethyl-1,2,3,7,8,8ahexahydronaphthalen-1-yl] 2,2-dimethylbutanoate It is used for the treatment of hypercholesterolemia ${ }^{1}$. Following conversion of this lactone prodrug to its hydroxyl acid form, the compound is a potent competitive inhibitor of HMGCoA reductase, the rate limiting enzyme in cholesterol biosynthesis ${ }^{2}$. Different analytical methods have been reported for the determination of simvastatin, which include HPLC ${ }^{3-6}$, HPLC-MS/MS 7 , derivative spectrophotometry ${ }^{8}$ and Voltammetric techniques?.<smiles>CCC(C)(C)C(=O)O[C@H]1C[C@@H](C)C=C2C=C[C@H](C)[C@H](CC[C@@H]3C[C@@H](O)CC(=O)O3)[C@]21C</smiles>

Fig. 1. Chemical structure of simvastatin

Ezetimibe (Fig.2), a selective inhibitor of intestinal cholesterol and related phytosterol absorption, is designated as 1-(4-fluorophenyl)-3(R)-[3-(4fluorophenyl)-3(S)-hydroxypropyl]- 4(S)-(4-hydroxyphenyl)-2-azetidinone. It prevents transport of cholesterol through the intestinal wall by selectively blocking the absorption of cholesterol from dietary and billiary sources. This reduces the overall delivery of cholesterol to the liver, thereby promoting the synthesis of LDL receptors and a subsequent reduction in serum LDL- $\mathrm{C}^{10-11}$. Very few HPLC methods for the determination of ezetimibe are reported in literature ${ }^{12-13}$.

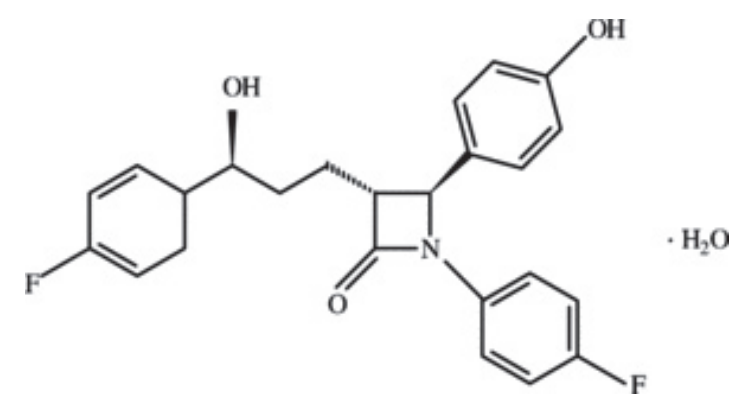

Fig. 2. Chemical structure of ezetimibe

In spite of the wide use of this fixed dose combination of drug, simultaneous determination of these components in their pharmaceutical formulations is not reported in literature to date. The work includes in this paper is therefore focused on to achieve the optimum chromatographic conditions for the simultaneous determination of ezetimibe and simvastatin in their fixed dose combination. We describe herein a simple, sensitive and validated HPLC method with isocratic elution for the simultaneous determination of ezetimibe and simvastatin in tablet formulations. Because of these features, the developed method can be successfully used in routine quality control work and for other analytical purposes.

\section{EXPERIMENTAL}

\section{Chemicals and Reagents}

Standard ezetimibe and simvastatin with claimed purity of 99.76 and $99.66 \%$ respectively were kindly donated by Schazoo Laboratories, Lahore (Pakistan). Vytorin tablets (10/10) which contain ezetimibe and simvastatin were purchased from the local market. Acetonitrile (HPLC grade), ammonium acetate and acetic acid glacial (analytical reagent grade) were purchased from Merck and de-ionized water was used throughout the experiment.

\section{Apparatus and chromatographic conditions}

HPLC apparatus consisting of Shimadzu LC-10A system equipped with a model LC-10AT pump, an SPD-10A variable wavelength detector (set at 240nm), a CBM-10A interface module with class LC-10 HPLC software and a Rheodyne injection valve with a $20 \mu \mathrm{L}$ loop was used for development and evaluation of this method. Chromatographic separation was performed using a Merck C-18 column ( $250 * 4.6$, i.d., $5 \mu \mathrm{m}$ particle size) with isocratic elution. The mobile phase consisted of a mixture of $0.1 \mathrm{M}$ ammonium acetate buffer $\mathrm{pH} 5.0$ and acetonitrile in the ratio of $(30: 70, \mathrm{v} / \mathrm{v})$ with flow rate as $1.5 \mathrm{mlmin}$ 1. Peak identity was confirmed by retention time comparison and the HPLC system was operated at room temperature. 


\section{Preparation of mobile phase}

A mobile phase was prepared by mixing $0.1 \mathrm{M}$ ammonium acetate buffer $\mathrm{pH} 5.0$ and acetonitrile in the ratio of 30:70, $/ / \mathrm{v}$. The mobile phase was filtered using $0.45 \mu$ nylon filters (Millipore, USA) and was degassed by sonication before use.

\section{Preparation of standard solution}

A stock standard solution containing $0.4 \mathrm{mgml}^{-1}$ each of ezetimibe and simvastatin was prepared by dissolving $20 \mathrm{mg}$ each of ezetimibe and simvastatin in mobile phase in $50 \mathrm{ml}$ volumetric flask and raising the volume up to the mark. To prepare the working standard solution $\left(40 \mu \mathrm{gml}^{-1}\right.$ for both ezetimibe and simvastatin), the stock standard solution was diluted with mobile phase.

\section{Preparation of sample solution}

Twenty tablets were weighed to get the average weight and then they were homogenized by grinding. An accurately weighed quantity of homogenized powder equivalent to $20 \mathrm{mg}$ each of ezetimibe and simvastatin was placed in $50 \mathrm{ml}$ volumetric flask. $30 \mathrm{ml}$ mobile phase was added and the flask was shaken for 5 minutes, so as to completely extract all the drugs. The volume was then made up to the mark with mobile phase to get a solution containing $0.4 \mathrm{mgml}^{-1}$ ezetimibe and $0.4 \mathrm{mgml}^{-1}$ simvastatin. Solution was then filtered using Whatmann filter paper No. 41 manually using a glass funnel and diluted with mobile phase to obtain a final concentration of $40 \mathrm{\mu gml}^{-1}$, ezetimibe and $40 \mathrm{\mu gml}^{-1}$ simvastatin.

\section{RESULTS AND DISCUSSION}

\section{Method Development and Optimization}

Simvastatin is an official drug in United States Pharmacoepia ${ }^{14}$ while ezetimibe is not found in any Pharmacoepial convention. The HPLC method for simvastatin tablets described by USP uses phosphate buffer $\mathrm{pH} 4.5$ and acetonitrile in the ratio of 35:65 (v/v) as a mobile phase and C8 column as stationary phase. The column temperature is maintained at $45^{\circ} \mathrm{C}$. The USP method therefore offers stringent chromatographic conditions that can also have a negative impact on the column life.

The aim of the present study was to develop a simple, isocratic, accurate and sensitive HPLC method for the simultaneous determination of ezetimibe and simvastatin in their fixed dose combination. Initially various mobile phases and stationery phases were tested to obtain the best separation and resolution between ezetimibe and simvastatin. The mobile phase consisting of $0.1 \mathrm{M}$ ammonium acetate buffer $\mathrm{pH} 5.0$ and acetonitrile in the ratio of $(30: 70, \mathrm{v} / \mathrm{v})$ was found appropriate for separation of both the components using a Merck C-18 column. The chromatographic conditions were optimized to get best resolution between the two analytes. The mobile phase composition was varied from 40:60 (v/v) buffer-acetonitrile to 20:80 (v/v) buffer-acetonitrile, in order to assess the impact of the acetonitrile content on the separation and chromatographic parameters like resolution, tailing factor and number of theoretical plates. Although increase of acetonitrile contents to $80 \%$ reduced the retention time of simvastatin to 6 minutes and resolution between ezetimibe and simvastatin to about 7 but tailing was greater than 1.3 with fewer theoretical plates as compared to the plates obtained using optimum mobile phase composition (30:70, v/v buffer-acetonitrile). The decrease of acetonitrile contents to $60 \%$ resulted in the elution of simvastatin after 18 minutes with almost the same tailing factor. So by applying the optimum chromatographic conditions, resolved sharp peaks that belong to ezetimibe and simvastatin were obtained at retention times of 2.95 and 9.80 minutes respectively [Figure 3 and 4].

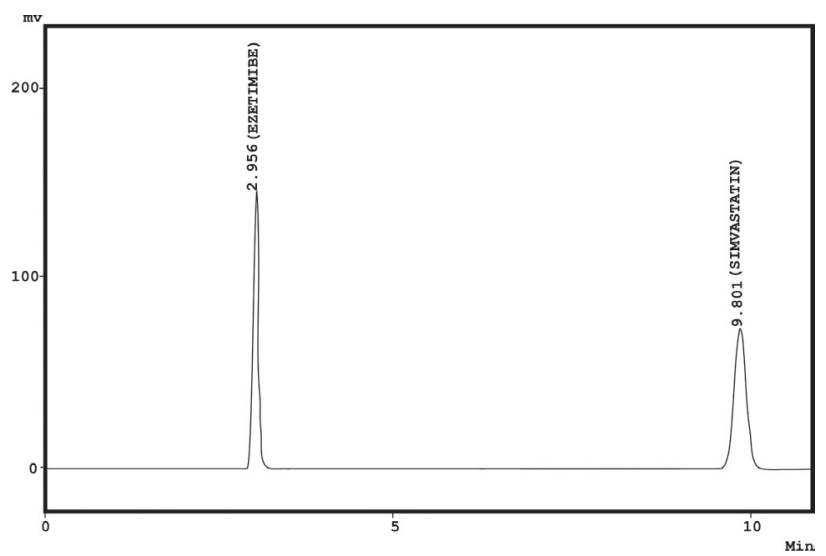

Fig. 3. Chromatograms of ezetimibe and simvastatin reference substance Chromatographic conditions; Wavelength $240 \mathrm{~nm}$, mobile phase ammonium acetate buffer $\mathrm{pH} 5.0$ and acetonitrile $(30: 70, \mathrm{v} / \mathrm{v})$, column C-18 $(250 * 4.6 \mathrm{~mm}$, $5 \mu \mathrm{m})$ at a flow rate of $1.5 \mathrm{mlmin}^{-1}$

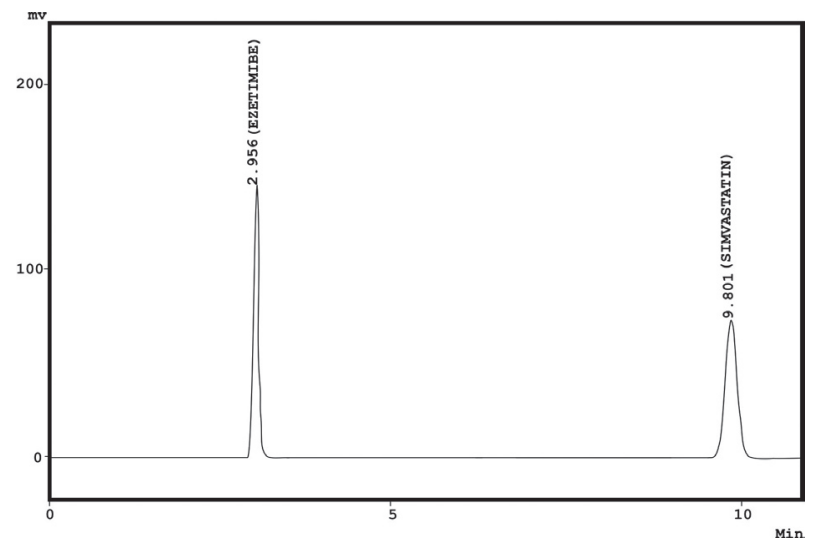

Fig. 4. Chromatograms of ezetimibe and simvastatin Tablets Chromatographic conditions; Wavelength $240 \mathrm{~nm}$, mobile phase ammonium acetate buffer $\mathrm{pH} 5.0$ and acetonitrile $(30: 70, \mathrm{v} / \mathrm{v})$, column C-18 $(250 * 4.6 \mathrm{~mm}$, $5 \mu \mathrm{m})$ at a flow rate of $1.5 \mathrm{mlmin}^{-1}$

\section{Method validation}

The developed chromatographic method for the simultaneous determination of ezetimibe and simvastatin was validated using ICH guidelines ${ }^{15,16}$. Assessed validation parameters include linearity, limit of quantitation, selectivity, accuracy and repeatability.

\subsection{Linearity}

Linearity of the proposed method was done by analyzing five solutions in the range of 20-60 $\mathrm{gml}^{-1}$ for both ezetimibe and simvastatin $(20,30,40$, 50 and $60 \mu \mathrm{gml}^{-1}$ ). Each concentration was used in triplicate. Good linearity was observed over the above range for both ezetimibe and simvastatin. The calibration curve was made using concentration of the analytes versus peak area The correlation coefficient from the linear regression analysis was calculated and found to be greater than 0.9996 in case of both the analytes. This indicates that there exists a good linear relationship between concentration of drugs and the peak area. The linear regression analysis data is given in Table1. 
Table 1. Results of linearity of the proposed method

\begin{tabular}{|cccccccccc|}
\hline Drug & $\mathrm{n}$ & $\begin{array}{c}\text { Linearity range } \\
\left(\mu \mathrm{gml}^{-1}\right)\end{array}$ & $\begin{array}{c}\text { Intercept } \\
\text { Mean }\end{array}$ & SD & $\begin{array}{c}\text { Slope } \\
\text { Mean }\end{array}$ & SD & r2 & $\begin{array}{c}\mathrm{S}_{\mathrm{yx}^{*}} \\
(\mathrm{Kv})\end{array}$ \\
\hline Ezetimibe & 5 & $20-60$ & -0.00302 & 0.0001 & 0.01868 & 0.0002 & 0.9996 & 0.00436 \\
Simvastatin & 5 & $20-60$ & -0.00548 & 0.0001 & 0.02284 & 0.0003 & 0.9992 & 0.00482 \\
\hline
\end{tabular}

* Standard error of estimate

\subsection{Limit of quantitation}

Two types of solutions i.e. blank and spiked with known progressively decreasing concentrations of each analyte were prepared and analysed. The limit of quantification (LOQ) was then established by evaluating the minimum level at which the analyte can be readily quantified with accuracy (signal to noise ratio of 10:1). The limits of quantitation were found to be $0.19 \mu \mathrm{gml}^{-1}$ and $0.17 \mu \mathrm{gml}^{-1}$ for ezetimibe and simvastatin respectively.

\subsection{Accuracy}

The accuracy of the method was performed by adding known amounts of ezetimibe and simvastatin to placebo solution and then comparing the added amount with the observed amount. Three levels of solutions were made which correspond to 50,100 and $150 \%$ of the nominal analytical concentration. Each level was made in triplicate. The recovery range and the relative standard deviation for each of the analytes were found to be $99.12-101.50 \%$ and $0.38-1.38 \%$ respectively [Table.2].

Table 2. Results of recovery experiments of the proposed HPLC method.

\begin{tabular}{|lcccccc|}
\hline Drug & $\begin{array}{c}\text { Level } \\
(\%)\end{array}$ & $\mathrm{n}$ & $\begin{array}{c}\text { Concentration } \\
\left(\mu \mathrm{gml}^{-1}\right)\end{array}$ & $\begin{array}{c}\text { Amount recovered } \\
\left(\mu \mathrm{gml}^{-1}\right)\end{array}$ & $\begin{array}{c}\text { Recovery } \\
(\%)\end{array}$ & $\begin{array}{c}\text { RSD } \\
(\%)\end{array}$ \\
\hline Ezetimibe & 50 & 3 & 20.0 & 20.05 & 100.25 & 1.38 \\
& 100 & 3 & 40.0 & 39.65 & 99.12 & 0.68 \\
& 150 & 3 & 60.0 & 60.20 & 100.33 & 0.86 \\
Simvastatin & 50 & 3 & 20.0 & 20.30 & 101.50 & 0.38 \\
& 100 & 3 & 40.0 & 40.25 & 100.62 & 1.15 \\
& 150 & 3 & 60.0 & 60.60 & 101.00 & 1.02 \\
\hline
\end{tabular}

\subsection{Precision}

The within-day precision was based upon the results of five replicate analyses of three different concentrations of analytes on a single day. The between-day precision was determined from the same samples analyzed for three consecutive days. The results of within-day and between-day precision are given in Table.3.

Table 3. Within and Between-day precision of the proposed HPLC method

\begin{tabular}{|cccccccc|}
\hline Compound & $\begin{array}{c}\text { Conc. } \\
\left(\mu \mathrm{gml}^{-1}\right)\end{array}$ & $\mathrm{n}$ & \multicolumn{2}{c}{$\begin{array}{c}\text { Within-day precision } \\
\text { Mean }\end{array}$} & \multicolumn{2}{c|}{$\begin{array}{c}\text { Between-day precision } \\
\text { Mean }\end{array}$} & RSD (\%) \\
\hline \multirow{2}{*}{ Ezetimibe } & 20.0 & 5 & 19.86 & 1.10 & 19.95 & 0.78 \\
& 40.0 & 5 & 40.12 & 1.05 & 39.90 & 1.15 \\
& 60.0 & 5 & 59.96 & 0.28 & 60.12 & 1.20 \\
Simvastatin & 20.0 & 5 & 20.24 & 1.45 & 20.10 & 0.56 \\
& 40.0 & 5 & 40.56 & 0.68 & 39.75 & 1.32 \\
& 60.0 & 5 & 59.42 & 0.75 & 60.25 & 0.88 \\
\hline
\end{tabular}

\subsection{Selectivity}

Selectivity of the proposed method was checked by making a synthetic mixture of both the analytes with commonly occurring excipients that are found in most tablet formulations and then measuring the percentage recovery of each component along with chromatographic parameters. The results show no interference from the excipients [Table. 4].

Table 4. Selectivity and system suitability of the proposed HPLC method

\begin{tabular}{|l|lccccc|}
\hline Drugs & \%age recovery & R.T* & Resolution & Tailing Factor & Theoretical Plates \\
\hline Ezetimibe & 100.62 & 2.96 & - & 1.23 & 6781 \\
Simvastatin & 99.43 & 9.80 & 19.64 & 1.06 & 13752 \\
\hline
\end{tabular}

\subsection{Stability}

The stability of each component in the presence of other was assessed by analyzing the samples after 24,48 and 72 hrs. The relative standard deviation of peak area was less than $0.44 \%$. The results are presented in Table. 5 which indicates good stability for each drug. 
Table 5. Stability study of ezetimibe and simvastatin in solution over 72 hours.

\begin{tabular}{|ccccc|}
\hline $\begin{array}{c}\text { Concentration } \\
\left(\mu \mathrm{gml}^{-1}\right)\end{array}$ & $\begin{array}{c}\text { Recovered concentration } \\
\left(\mu \mathrm{gml}^{-1}\right)\end{array}$ & & \\
& After 24hrs & After 48hrs & After 72hrs & RSD (\%) \\
\hline 1-Ezetimibe & & & & \\
20.0 & 20.32 & 20.09 & 19.85 & 0.24 \\
40.0 & 40.76 & 39.90 & 40.40 & 0.43 \\
60.0 & 59.70 & 60.25 & 60.56 & 0.44 \\
2-Simvastatin & & & & \\
20.0 & 20.12 & 19.95 & 20.05 & 0.08 \\
40.0 & 40.35 & 40.25 & 40.20 & 0.08 \\
60.0 & 60.15 & 60.25 & 59.75 & 0.26 \\
\hline
\end{tabular}

\section{Application of the method}

The proposed HPLC method was applied for the determination of ezetimibe and simvastatin in their combined pharmaceutical formulations [Table.6]. The recovery of the data and the agreement between the label claim and the amount found were excellent. This confirms the suitability of the proposed method for the routine quality control determination of these components in pharmaceutical formulations.

Table.6. Results of analysis of ezetimibe and simvastatin in tablets.

\begin{tabular}{|lccccc|}
\hline Drug & $\mathrm{n}$ & $\begin{array}{c}\text { Amount claimed } \\
\text { (mg per tablet) }\end{array}$ & $\begin{array}{c}\text { Amount found } \\
\text { (mg per tablet) }\end{array}$ & $\begin{array}{c}\text { Mean Recovery } \\
(\%)\end{array}$ & $\begin{array}{c}\text { RSD } \\
(\%)\end{array}$ \\
\hline Ezetimibe & 5 & 10 & 10.12 & 101.25 & 0.75 \\
Simvastatin & 5 & 10 & 10.05 & 100.50 & 1.15 \\
\hline
\end{tabular}

\section{CONCLUSION}

Simultaneous determination of ezetimibe and Simvastatin in their pharmaceutical formulation has been successfully achieved by the use of a validated analytical method. The method is accurate and precise for reliable quality control evaluation of drugs with good accuracy and precision. From these values it is concluded that the new HPLC method is suitable for the simultaneous determination of these two components in their pharmaceutical formulations.

\section{REFERENCES}

1. V. F. Mauro. Clin. Pharmacokinet. 24, 195 (1993)

2. A. W. Alberts, J. Chen, G. Kuron, V. Hunt, J. Huff, C. Hoffman, J. Rothrock, M. Lopez, H. Joshua, E. Harris, A. Patchett, R. Monaghan, S. Currie, E. Stapley, G. Albers-Schonberg, O. Hensens, J. Hirshfield, K. Hoogsteen, J. Liesch, and J. Springer. Proc. Natl. Acad. Sci. USA. 77, 3957 (1980)

3. G. Carlucci, P. Mazzeo, L. Biordi, M. Bologna. J. Pharm. Biomed. Anal. 10(9), 693 (1992)

4. H. Ochiai, N. Uchiyama, K. Imagaki, S. Hata, T. Kamei. J. Chromatogr. B Biomed. Sci. Appl. 694(1), 211 (1997)

5. L. Tan, L. L. Yang, X. Zhang, Y. S. Yuan, S. S. Ling. Se Pu. 18(3), 232 (2000).

6. A. Malenovic, D. Ivanovic, M. Medenica, B. Jancic, S. Markovic . J Sep. Sci. 27(13), 1087 (2004).

7. B. Barrett, J. Huclova, V. Borek-Dohalsky,B. Nemec, I. Jelinek. J. Pharm. Biomed. Anal. 41(2), 517 (2006).

8. L. Wang, M. Asgharnejad .J. Pharm. Biomed. Anal. 21(6), 1243 (2000).

9. O. Coruh, S. A. Ozkan. Pharmazie. 61(4), 285 (2006)

10. E. Leitersdorf. Int. J. Clin. Pract. 56(2), 116 (2002).

11. M.Von Heek, C. Farley, D.S. Compton. Br. J. Phamacol. 134, 409 (2001).

12. S. Singh, B. Singh, R. Bahuguna, L. Wadhwa, R. Saxena. J. Pharm. Biomed. Anal. 41(3), 1037 (2006).

13. R. Sistla, V. S.Tata, Y. V. Kashyap, D. Chandrasekar, P. V. Diwan. J. Pharm. Biomed. Anal. 39(3-4), 517 (2005).

14. USP 29-NF 24 (2006), 1965-66. The United States Pharmacoepial Convention 12601, Twinbrook Parkway, Rockville, MD 20852.

15. ICH (Q2A)(1994) Note for guidance on validation of analytical methods: definition and terminology. International conference on Harmonisation, IFPMA, Geneva.

16. ICH (Q2B)(1996) Note for guidance on validation of analytical procedures: methodology. International conference on Harmonisation, IFPMA, Geneva. 